\title{
PENGEMBANGAN POTENSI WISATA BAHARI BERBASIS MASYARAKAT DI PULAU PASARAN, BANDAR LAMPUNG
}

\section{THE DEVELOPMENT OF COMMUNITY-BASED MARINE TOURISM IN PASARAN ISLAND, BANDAR LAMPUNG}

\author{
Nuning Mahmudah Noor'), Deny Sapto Chondro Utomo ${ }^{2)}$, Andrya Yunila Hastuti' ${ }^{3)}$ \\ Ahmad Habibi ${ }^{4)}$ dan Mahrus Ali ${ }^{5}$ ) \\ Program Studi Budidaya Perikanan, Jurusan Peternakan, Politeknik Negeri Lampung \\ Jl. Sukarno Hatta No. 10, Rajabasa, Bandar Lampung \\ Surel: nuning@polinela.ac.id \\ Jurusan Perikanan dan Kelautan, Fakultas Pertanian, Universitas Lampung \\ Jl. Soemantri Brojonegoro No. 1, Gedong Meneng, Bandar Lampung \\ Badan Perencanaan Pembangunan Daerah (Bappeda) Kota Bandar Lampung \\ Jl. Kartini 12-E, Gn. Sari, Kota Bandar Lampung, Lampung 35127 \\ Fakultas Ekonomi dan Bisnis Islam, Universitas Islam Negeri Raden Intan Lampung \\ Jl. Letnan Kolonel H. Endro Suratmin, Sukarame, Kota Bandar Lampung, 35131
}

Dikirim 15 Februari 2021, Direvisi 12 Maret 2021, Disetujui 5 Maret 2021

\begin{abstract}
Abstrak: Pulau Pasaran merupakan penghasil utama ikan teri di Lampung, disamping juga penghasil ikan budidaya dan kerang hijau. Potensi perikanan tersebut menjadi daya tarik tersendiri terlebih karena lokasi pulau yang berada di perkotaan (Kota Bandar Lampung). Pulau Pasaran yang hanya seluas 12,5 hektar ini berpotensi tidak hanya sebagai sentra produksi perikanan, namun juga wisata bahari (minawisata). Konsep minawisata yang diusung adalah dengan lebih menitikberatkan peran aktif komunitas dan mengakui hak masyarakat lokal dalam pengelolaan pariwisata di kawasan mereka (community-based marine tourism). Beberapa program telah berhasil dijalankan dalam rangka mendukung minawisata Pulau Pasaran, diantaranya: perancangan minawisata, peningkatan sanitasi pulau, penguatan kelembagaan, pembangunan sarana dan prasarana, pengembangan produk perikanan, dan penguatan promosi. Sehingga Pulau Pasaran menjadi icon baru minawisata yang dapat menguntungkan bagi Kota Bandar Lampung (PAD) dan dapat meningkatkan kesejahteraan masyarakat secara langsung.
\end{abstract}

Kata kunci: Pulau Pasaran, minawisata, berbasis masyarakat

\begin{abstract}
Pasaran Island is not only well-known as a major producer of anchovies in Lampung province, but also as a mariculture location of some fish and green mussel. The island which only covers 12.5 hectares is located in urban areas, in Bandar Lampung City, the capital of Lampung province. Pasaran Island has the potential as a fishery production center and marine tourism (minawisata). The minawisata concept emphasizing the active role and rights of the local communities in the management of tourism in their area (community-based marine tourism). Several programs for the development of minawisata on Pasaran island have been successfully implemented, including: designing minawisata, enhancing sanitation, strengthening institutions, building facilities and infrastructure, developing fishery products, and strengthening promotions. Pasaran Island would therefore be a new marine-tourism icon that beneficial to Bandar Lampung City and directly boost the local community's welfare.
\end{abstract}

Keywords: Pasaran island, mirne tourism, community-based

\section{PENDAHULUAN}

Pulau Pasaran merupakan sentra perikanan di Lampung khususnya produk ikan teri asin. Terdapat beberapa jenis ikan teri yang diproduksi di Pulau Pasaran seperti teri nasi, teri jengki, teri nilon, teri katak dan teri puntiaw di samping juga terdapat cumi dan jenis ikan lain yang diolah menjadi ikan asin (salted-dryed) (Ali et al., 2018).

Tidak hanya ikan teri, potensi Pulau Pasaran sangat beragam diantaranya kerang hijau, budidaya kerapu, ikan simba dan kakap putih (Noor, 2015; Putri et al., 2018; Noor et al., 2019a), budaya masyarakat 
yang unik, aktifitas perikanan lain seperti pembuatan perahu, serta potensi komunitas mangrove di dalamnya yang dapat menjadi daya tarik dari Pulau Pasaran.

Keunikan lain dari Pulau Pasaran adalah karena letaknya yang berdekatan dengan ibu kota provinsi, mudahnya akses terutama setelah dibangun jembatan penyeberangan sepanjang 200 meter yang menghubungkan Pulau Pasaran dan Kota Bandar Lampung sehingga mudah disinggahi (Ali, 2015).

Secara administratif Pulau Pasaran terletak di Kecamatan Teluk Betung Barat dengan luas wilayah sebesar 12,5 hektar ini memiliki penduduk 1.171 jiwa yang terdiri atas 574 orang laki-laki dan 597 orang perempuan atau 224 kepala keluarga (Tabel 1) (Monograf Pulau Pasaran, 2018).

Di satu sisi sektor pariwisata merupakan sektor yang prospektif bagi Kota Bandar Lampung. Hal ini juga terlihat dari Rencana Pembangunan Jangka Menengah Daerah (RPJMD) Tahun 2016-2021 yang salah satunya adalah pengembangan jasa dan perdagangan berbasis ekonomi kerakyatan dan pengembangan pariwisata.

Melihat potensi yang dimiliki Pulau Pasaran, maka konsep wisata bahari (minawisata) sangat relevan untuk pengembangan Pulau Pasaran. Minawisata didefinisikan sebagai cabang pariwisata yang berfokus pada pemanfaatan potensi dan keindahan flora, fauna, budaya dan nuansa bahari dalam suatu kawasan tertentu (Waryono, 2000).

Dengan menjadikan Pulau Pasaran sebagai destinasi wisata bahari akan meningkatkan daya tawar Pulau Pasaran dan meningkatkan pendapatan masyarakat lokal. Oleh sebab itu peran masyarakat perlu ditingkatkan dalam pengelolaan wisata ini. Konsep ini dikenal dengan community-based marine tourism yang lebih menitikberatkan peran aktif dari komunitas masyarakat lokal dalam pengelolaan pariwisata di kawasan mereka.

Pengembangan konsep minawisata berbasis masyarakat dapat meningkatkan kesejahteraan seiring munculnya berbagai usaha dari pembentukan minawisata. Guna mewujudkan konsep tersebut maka diperlukan berbagai upaya, pembinaan, pengelolaaan, sarana dan prasarana penunjang maupun promosi.

Tabel 1. Pengelompokan penduduk

\begin{tabular}{ll}
\hline $\begin{array}{l}\text { Klasifikasi Pendududuk } \\
\text { Pulau Pasaran }\end{array}$ & $\begin{array}{l}\text { Jumlah } \\
\text { (jiwa) }\end{array}$ \\
\hline $\begin{array}{l}\text { Berdasarkan jenis kelamin } \\
\text { - Laki-laki }\end{array}$ & 574 \\
- Perempuan & 597 \\
\hline \multicolumn{2}{l}{ Berdasarkan pekerjaan } \\
- TNI & - \\
- Nelayan & 375 \\
- PNS & 6 \\
- Pengusaha ikan asin & 205 \\
- Penjual jasa/ buruh & 392 \\
- Lainnya & 310 \\
\hline Berdasarkan pendidikan & \\
- Perguruan Tinggi & 5 \\
- SMU & 116 \\
- SLTP & 234 \\
- SD & 532 \\
- Tidak Sekolah & 277 \\
\hline
\end{tabular}

(Sumber: Data Pulau Pasaran, 2018)

\section{METODOLOGI}

Kajian ini dilakukan di Pulau Pasaran, Kecamatan Teluk Betung Barat, Kota Bandar Lampung di mana pemilihan lokasi dilakukan secara sengaja (purposive) karena memiliki potensi untuk dijadikan sebagai areal wisata bahari yang dekat dengan ibu kota provinsi. Program yang dijalankan meliputi: observasi potensi pariwisata, focus group discussion (FGD), perencanaan program, pelaksanaan dan evaluasi.

Proses observasi dilakukan melalui pengamatan secara langsung dan interview dengan tokoh masyarakat. Proses ini bertujuan untuk mendapatkan informasi dasar potensi minawisata Pulau Pasaran, juga dilakukan penyebaran kuisioner didukung wawancara mendalam (indepth interview) dengan ahli (Arikunto, 2002). 
FGD dilakukan untuk menggali informasi secara luas dengan cara mengumpulkan data dari stakeholder secara bersamaan dalam satu kelompok diskusi. Proses FGD dilakukan dengan tokoh masyarakat Pulau Pasaran, Dinas Perikanan dan Bappeda Kota Bandar Lampung (Gambar 1). FGD ini berupaya merumuskan permasalahan minawisata Pulau Pasaran untuk selanjutnya dicarikan solusinya.

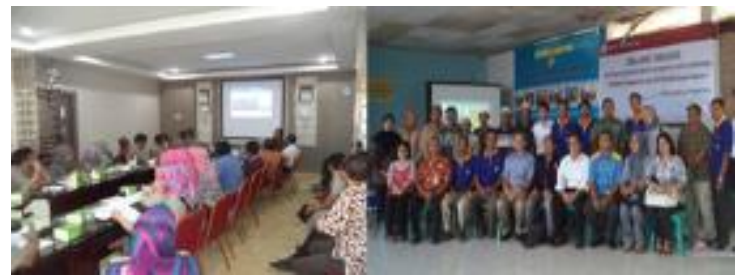

Gambar 1. FGD dengan pihak pemerintah daerah dan stakeholder

Tahapan perencanaan dilakukan guna merancang berbagai upaya yang dapat dilakukan berbagai pihak tekait guna mewujudkan minawisata Pulau Pasaran dan mengantisipasi permasalahan yang akan timbul. Pelaksanaan program dilakukan dengan melibatkan seluruh lapisan masyarakat Pulau Pasaran dan stakeholder serta evaluasi keberhasilan program yang bertujuan memberikan koreksi terhadap program yang dijalankan.

Sumber data dari tulisan ini yaitu data primer merupakan data dan informasi yang diperoleh dari kuisioner, wawancara yang berkenaan dengan penelitian dan data sekunder data yang telah tersusun dalam bentuk dokumen-dokumen tertulis, internet, dan jurnal. Seluruh data dan hasil kegiatan kemudian dilaporkan secara deskriptif.

\section{HASIL DAN PEMBAHASAN}

\section{Profil Pulau Pasaran}

Pulau Pasaran merupakan salah satu pulau di Kota Bandar Lampung yang secara administratif berada di Kecamatan Teluk Betung Barat. Berlokasi di sebelah selatan kota Bandar Lampung, dengan luas wilayah
12,5 ha, dan telah berpenghuni sejak tahun 1970an, dengan penduduk 224 kepala keluarga atau 1.173 jiwa.

Fasilitas umum yang ada di Pulau Pasaran, diantaranya: jalan kampung yang sudah dipaving selebar 1 meter, pusat kesehatan masyarakat, masjid, MCK umum, gedung pertemuan, gedung koperasi, suplai listrik PLN, dan air PDAM dengan pipa yang tertanam di bawah laut. Penduduk Pulau Pasaran mayoritas bersuku Jawa dan sisanya suku Bugis (Ali et al., 2015).

Keunikan Pulau Pasaran adalah terletak pada lokasinya yang menjadikan satusatunya pulau berpenduduk di areal perkotaan di Lampung. Akses ke Pulau Pasaran dapat ditempuh dengan jalur penyeberangan laut menggunakan perahu jukung atau jalur darat menggunakan jembatan yang bisa dilewati oleh pejalan kaki dan motor. Jembatan sepanjang 200 meter ini dibangun tahun 2013.

Sektor perikanan menempati urutan pertama dalam mata pencarian dan kegiatan ekonomi masyarakat. Disamping dikenal sebagai icon pengolahan ikan teri, masyarakat di Pulau Pasaran juga melakukan aktifitas penangkapan ikan, pengolahan cumi, dan ikan lainnya serta aktivitas budidaya kakap putih, ikan simba dan kerang hijau dengan menggunakan rakit apung (Tabel 2) (Ali et al., 2015b).

Pulau yang berjarak $6 \mathrm{~km}$ dari kota Bandar Lampung ini juga memiliki potensi komuditas mangrove seluas 10,8 ha dan memungkinkan dikembangkan hingga 10 ha lagi (KKP Kota Bandar Lampung, 2014). Hal ini menjadikan Pulau Pasaran memiliki potensi sebagai destinasi pariwisata bahari (minawisata) di perkotaan (Gambar 2). 


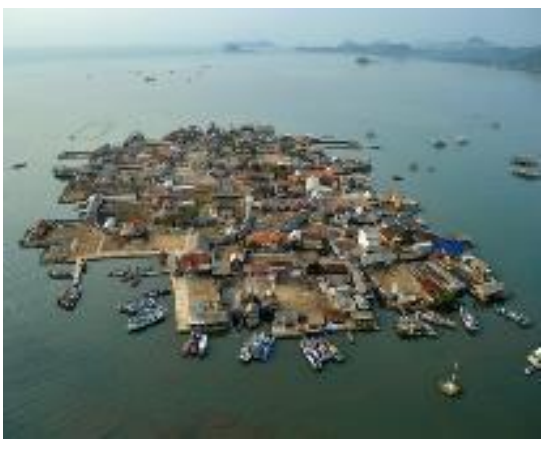

Gambar 2. Pulau Pasaran, Lampung

\section{Potensi minawisata Pulau Pasaran}

Minawisata merupakan wisata yang berfokus pada pemanfaatan kawasan wisata produksi perikanan dan kelautan secara terintegrasi pada suatu wilayah tertentu berupa kekayaan alam yang indah, keragaman flora dan fauna seperti terumbu karang dan berbagai jenis ikan hias (Waryono, 2000).

Beberapa jenis kegiatan minawisata yang saat ini sudah dikembangkan diantaranya wisata alam, pemancingan, berenang, selancar, berlayar, rekreasi pantai dan wisata pesiar. Menurut Inskeep (1991), bahwa untuk mengembangkan suatu kawasan wisata terdapat tujuh komponen yang saling berhubungan yaitu: daya tarik dan aktifitas wisata, pelayanan wisata, infrastruktur, transportasi, pemasaran promosi, regulasi, pelestarian lingkungan dan sosial ekonomi masyarakat setempat.

Menurut Ali (2015), konsep minawisata yang potensial dikembangkan di Pulau Pasaran adalah berbasis wisata produk perikanan dan budidaya perikanan serta ekowisata mangrove di perkotaan. Sementara hasil observasi dan diskusi (FGD) dengan masyarakat dan Dinas Perikanan Kota Bandar Lampung telah mengidentifikasi potensi minawisata Pulau Pasaran, diantaranya sebagai berikut:

1. Wisata budidaya laut (mariculture); pariwisata ini meliputi manajemen dan proses budidaya ikan kakap putih dan ikan simba di karamba jaring apung (KJA) (Noor et al., 2016). Pengunjung dapat memberi makan ikan dan berfoto di KJA. Aktifitas lainnya adalah budidaya dan pemanenan kerang hijau (Perna viridis) (Noor at al., 2019a; Noor et al., 2019b; Sulvina et al., 2015

2. Saat ini sudah terbentuk kelompok pembudidaya sebelas kerang hijau dengan masing-masing 10 rakit apung. Bahkan ada yang dibudidaya dengan sistem polikultur antara kerang dan ikan (Hidayat et al., 2019). Hasil panen bisa dibeli secara langsung oleh pengunjung dengan harga yang relatif lebih murah dari pada harga di pasar lelang (PPI).

3. Wisata olahraga dan memancing (sport and recreation fishing); wisata ini meliputi penangkapan ikan teri, cumi dan kepiting bakau. Penangkapan ikan teri di Pulau Pasaran dilakukan secara tradisional baik menggunakan bagan dan menggunakan perahu.

Biasanya nelayan berangkat melaut jam 15.00 WIB dan merapat jam 07.00 WIB dengan fising ground berada di sekitar Teluk Lampung. Aktifitas menangkap ikan teri ini unik karena wisatawan dapat bermalam di bagan ikan (lift net) dan menunggu ikan datang. Tidak hanya itu, keunikan lainnya adalah proses pengolahan ikan teri yang dilakukan di atas perahu secara langsung begitu ikan teri ditangkap sehingga kualitasnya masih bagus.

Proses pemancingan cumi (Loligo indiga), namun masih musiman. Potensi cumi di Perairan Pulau Pasaran tergolong tinggi. Aktifitas ini terutama berlangsung saat awal bulan dengan menggunakan pancing cumi yang telah didesign khusus.

Sementara penangkapan kepiting bakau (Scella serata) dilakukan dengan dua cara yaitu menggunakan metode langsung (galah) yang dilakukan pada petang hari ataupun menggunakan perangkap yang pasang di sekitar mangrove di sekitar Pulau Pasaran.

4. Wisata produk perikanan; Pulau Pasaran terkenal sebagai sentra pengolah ikan teri dengan produksi sekitar 180 ton/ bulan (DKP Kota 
Bandar Lampung, 2014). Saat ini terdapat 59 kelompok pengolah ikan teri ini (Ali et al., 2015a). Pengunjung dapat melihat langsung proses perebusan, pengeringan, dan packing produk perikanan. Di samping juga dapat berbelanja ikan, cumi, kerang dan kepiting segar pengunjung juga dapat berbelanja produk turunan ikan teri yakni ikan teri yang dikemas vacum (teri siger), stick teri, getas teri, kripik teri, teri gulung, dan teri wijen yang merupakan produk dari ibu-ibu nelayan di Pulau Pasaran (Ali et al., 2018; Sulistiyanti et al., 2016).

5. Wisata lingkungan dan konservasi; jenis wisata ini dapat berupa: ekowisata mangrove, pendidikan konservasi, praktek menanam bibit mangrove, dan transplantasi karang. Menurut KKP Kota Bandar Lampung (2014), ekosistem mangrove di Pulau Pasaran terdiri dari Sonnetaria dan Avicennia yang terbentang seluas 10,8 ha di bibir pantai dengan ketebalan 5-30 meter. Komunitas mangrove ini belum dikelola dengan baik sehingga melalui ekowisata akan meningkatkan potensi ekologis dan ekonomis mangrove tersebut (Ali, 2015).

6. Potensi lainnya adalah terumbu karang terutama di perairan sekitar Pulau Mutiara (30 menit dari Pulau Pasaran). Hamparan terumbu karangnya berada pada kedalaman 1-2 meter dan masih dalam kondisi, sehingga cocok untuk spot snorkeling. Pengamatan lapang terdapat 8 genus terumbu karang yang ditemukan, yaitu: Acropora, Fungia, Echinopora, Goniastrea, Montipora, Pectinia, Pocilopora, dan Porites. Sementara komunitas lamun (seagrass) di perairan Pulau Pasaran dan Pulau Mutiara masih padat terutama dari jenis Enhalus, Thallasia, dan Cymodocea.

\section{Penguatan Minawisata}

Potensi dan keberagaman minawisata di Pulau Pasaran yang demikian besar tersebut belum dikelola, dipromosikan serta dikembangkan secara optimal. Berdasarkan hasil analisis SWOT yang dilakukan oleh Ali (2015), dipetakan permasalahan dan rekomendasi program guna mewujudkan program minawisata Pulau Pasaran. Permasalahan utama yang dihadapi adalah: rendahnya sanitasi di Pulau Pasaran, minimnya sarana dan fasiltas pendukung, rendahmya SDM terlatih, serta penyediaan informasi pariwisata yang minim.

Oleh sebab itu disusun program guna pengembangan Pulau Pasaran sebagai areal minawisata di Kota Bandar Lampung, diantaranya: perencanaan, peningkatan sanitasi pulau, penguatan kelembagaan, pembangunan sarana dan prasarana, pengembangan produk ikan, penguatan promosi dan beberapa program lainnya.

\section{Perencanaan program}

Peran pemerintah sangat penting dalam pengembangan minawisata. Paket kebijakan diperlukan untuk mendorong wisata terutama pembangunan infrastruktur dan suprastruktur (Amanah dan Utami, 2006). Beberapa kebijakan yang sejalan dengan pengembangan minawisata Pulau Pasaran yakni pada tahun 2010 Pulau Pasaran telah ditetapkan sebagai Kawasan Minapolitan oleh Kementerian Kelautan dan Perikanan (SK Menteri KKP No. 32 Tahun 2010).

Hal tersebut mendasari pembentukan Tim Pelaksana Pembangunan Klaster Ikan di Pulau Pasaran oleh Wali Kota Bandar Lampung (SK Wali Kota Bandar Lampung Nomor 256/23/HK/2011) dengan mengadopsi pola kerjasama ABG (academic-business-government) yang beranggotakan unsur pemerintah daerah, Bank Indonesia, dan Universitas Lampung.

Selanjutnya pada tahun 2012 Direktorat Jenderal Pengolahan dan Pemasaran Hasil Perikanan (P2HP) KKP membentuk tim Teknis Pembina Sentra Pengolahan Hasil Perikanan Surat Keputusan Dirjen Nomor 
KEP.76/DJ-P2HP/2012. Kemudian tahun 2014 tim pembinaan masyarakat dari Politeknik Negeri Lampung berpartisipasi melalui program Iptekda LIPI untuk mengembangkan budidaya kerang hijau.

Selanjutnya pemerintah Kota Bandar Lampung juga telah menyusun detail engineering design (DED) Pulau Pasaran. Penyusunan DED ini merupakan upaya membuat grand design pembangunan Pulau Pasaran ke depan (Dinas Tata Kota Bandar Lampung, 2013). Di dalamnya tercantum berbagai berbagai informasi mengenai pembangunan fasiltas, konstruksi, pengembangan dan lain sebagainya yang dapat menjadi patokan dalam penyusunan program di Pulau Pasaran.

\section{Peningkatan sanitasi Pulau Pasaran}

Pulau Pasaran merupakan daerah dataran rendah yang memiliki ketinggian 02 meter di atas permukaan laut. Pada tahun 1963 luas pulau tercatat hanya 2,5 hektar dengan dominasi tanaman kelapa di sekeliling pulau, sementara saat ini mencapai 12,5 hektar. Pertambahan luas ini dikarenakan reklamasi (penimbunan pulau) yang dilakukan oleh penduduk pulau untuk kepentingan pemukiman dan lahan penjemuran ikan teri (Bapeda Kota Bandar Lampung, 2012; Pulau Pasaran, 2018). Hal ini menjadikan Pulau Pasaran mudah mendapatkan limpahan sampah dari luar karena ketika pasang tertingi sekita 30-40\% areal pulau akan terendam air laut. Sehingga diperlukan pengelolaan sampah agar tidak mencemari lingkungan.

Beberapa program telah dijalankan guna menanggulangi limbah dan menjaga aspek sanitasi Pulau Pasaran diantaranya pemberian peralatan sanitasi warga, gerakan jaring sampah (GJS), pembentukan masyarakat sadar lingkungan hingga membangun Bank Sampah. Pemberian peralatan sanitasi berupa tempat sampah sebanyak 30 buah yang disebar di seluruh areal pulau guna menampung limbah sehari-hari, juga kendaraan roda tiga oleh Dinas Tata Kota Bandar Lampung untuk mengangkut sampah dari Pulau Pasaran ke Tempat Pembuangan Sampah Sementara (TPS).

Gerakan Jaring Sampah (GJS) dilakukan oleh masyarakat bersama-sama dengan Jurusan Perikanan Universitas Lampung. Sampah dikordinir oleh masyarakat untuk selanjutnya dibung ke TPS. Di samping itu juga diberikan pelatihan sanitasi keluarga dengan menitikberatkan pada cara hidup sehat, manajemen persampahan, maupun saluran air (drainase) di lingkungan Pulau Pasaran.

Pembentukan kelompok masyarakat sadar lingkungan (MY DARLING) berupaya untuk melestarikan kebersihan lingkungan dengan cara membentuk kelompok masyarakat Pulau yang peduli terhadap kesehatan lingkungan. Sasaran utama adalah pemuda pulau yang diharapkan melahirkan kegiatan-kegiatan yang dapat mendukung terciptanya kebersihan lingkungan Pulua Pasaran.

\section{Penguatan kelembagaan}

Usaha perikanan di Pulau Pasaran tidak terbatas pada usaha pengolahan, melainkan juga usaha budidaya (aquaculture) ikan kakap putih dan kerang hijau menggunakan jaring apung dan usaha penangkapan ikan ikan dan cumi (Noor, 2015). Usaha perikanan tersebut banyak menyerap tenaga kerja baik yang berasal dari luar pulau ataupun penduduk asli Pulau Pasaran. Tercatat setidaknya 810 orang yang bekerja di sektor perikanan (pengolahan) (DKP Kota Bandar Lampung, 2014).

Penguatan usaha ikan teri di Pulau Pasaran dimulai sejak tahun 2009 dengan dibentuknya klaster pengolahan ikan yang diinisiasi oleh Dinas Kelautan dan Perikanan Kota Bandar Lampung bersama Bank Indonsia Lampung melalui Program Pengembangan Ekonomi Lokal berbasis Komuditas Unggulan. Selanjutnya dibentuk Koperasi Nelayan Mitra Karya Bahari guna meningkatkan posisi tawar nelayan dan kelompok nelayan setempat (Noor, 2015). 
Penguatan dan pembinaan terhadap Koperasi Mitra Karya Bahari dilakukan melalui pembinaan pelaporan keuangan dan pelatihan kewirausahaan bagi pengurus koperasi.

Tabel 2. Aktifitas perokonomian perikanan

\begin{tabular}{lcl}
\hline $\begin{array}{l}\text { Kelompok } \\
\text { nelayan }\end{array}$ & Jumlah & Keterangan \\
\hline Penangkap ikan & 59 & $\begin{array}{l}\text { Hasil tangkapan } \\
\text { dominan ikan teri, } \\
\text { cumi, rajungan, } \\
\text { serta ikan rucah. }\end{array}$ \\
$\begin{array}{l}\text { Pembudidaya } \\
\text { kerang dan ikan }\end{array}$ & 11 & $\begin{array}{l}\text { Satu kelompok } \\
\text { pembudidaya ikan } \\
\text { dan sepuluh } \\
\text { pembudidaya } \\
\text { kerang hijau }\end{array}$ \\
Pengolah ikan & 7 & $\begin{array}{l}\text { Produk ikan teri } \\
\text { kering, cumi, rucah }\end{array}$ \\
Produk turunan & 2 & $\begin{array}{l}\text { Produk snack ikan } \\
\text { teri dan ikan teri } \\
\text { kemas vacum teri } \\
\text { siger }\end{array}$ \\
\hline
\end{tabular}

(Sumber: Ali et al., 2015)

\section{Pembangunan sarana dan prasarana}

Penyediaan sarana dan prasarana senantiasa terutama dilakukan oleh Pemerintah Kota Bandar Lampung seperti pembangunan jembatan penyeberangan dengan lebar 1,5 meter yang bisa dilewati oleh pejalan kaki dan motor. Jembatan sepanjang 200 meter menjadi penghubung Pulau Pasaran dengan daratan di Teluk Betung ini dibangun tahun 2013.

Penyediaan alat transportasi perahu sebanyak 2 buah yang dikelola oleh masyarakat Pulau Pasaran, serta pembuatan pembangunan lapangan pusat kegiatan warga seluas 2000 meter persegi dengan cara menimbun pantai di Pulau Pasaran yang dimaksudkan untuk memfasilitasi kegiatan warga.

Selanjutnya program sepeda wisata guna memfasilitasi pengunjung berkeliling menikmati keindahan Pulau Pasaran.

\section{Pengembangan produk perikanan}

Produk ikan teri asal Pulau Pasaran lebih dikenal sebagai teri medan sehingga keberadaan sentra produksi ikan teri Pulau Pasaran tidak diketahui oleh masyarakat luas. Maka dari itu digagas pembuatan produk ikan teri khas Pulau Pasaran dengan nama Teri Siger (Gambar 3).

Pemilihan nama siger didasarakan pada kebudayaan Lampung yang sudah dikenal oleh masyarakat luas. Produk didesign sedemikian rupa dengan menerapkan teknologi pengemasan vakum yang dapat memperpanjang masa awet produk ikan teri menjadi 3 bulan. Keunggulan lainnya dari segi higienisitas produk yang lebih terjaga dan terhindar dari kontaminasi kimia dan biologi serta menjadi media promosi bagi konsumen (Rosalina dan Prasetyo, 2010; Ali et al., 2015).

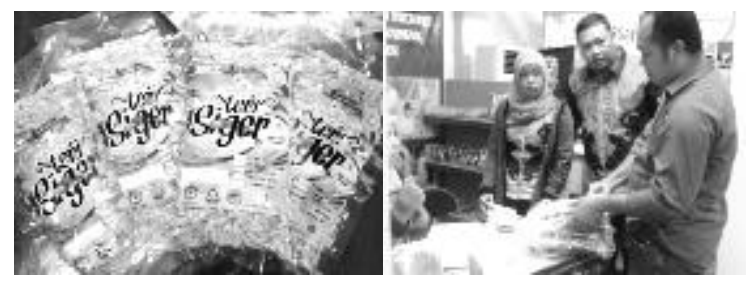

Gambar 3. Produk teri siger dan promosi melalui pameran

Pemasaran dilakukan secara langsung di lokasi pengolahan maupun dengan mengikutkan dalam pameran dan bazar tingkat lokal maupun nasional serta melalui metode daring. Pada akhir tahun 2015 Wali Kota Bandar Lampung mencanangkan Teri Siger sebagai produk khas dan icon produk perikanan Kota Bandar Lampung.

Pengembangan produk lain adalah dengan melakukan diversifikasi produk ikan teri menjadi produk turunan berupa makanan ringan seperti: teri kriuk, getas teri, keripik teri dan teri gulung. Olahan diversifikasi dilakukan guna meningkatkan nilai tambah dari teri dan menjadi solusi penanganan ketika produksi melimpah.

Beberapa event promosi yang diikuti guna memasarkan teri siger diantaranya: dikutsertakan dalam pameran dan lomba MTQ tingkat Lampung dan pameran pembangunan di Kota Bandar Lampung, 
Dies Natalis Universitas Lampung, pameran dalam rangka HUT Kota Bandar Lampung, Lampung Fair dan lain sebagainya.

\section{Promosi Pulau Pasaran}

Program promosi dimaksudkan untuk memasarkan potensi Pulau Pasaran kepada wisatawan. Beberapa program yag telah dijalankan diantaranya: penguatan public relation, penguatan image, festival Pulau Pasaran (Gambar 4), pencanangan minawisata dan pembangunan informasi secara daring serta membangun jejaring pariwisata.

Penguatan public relation telah dilakukan dengan mengundang jurnalis (visiting journalist program) dari media elektronik dan media cetak dan daring ke Pulau Pasaran. Tujuan utama program ini adalah menyediakan fasilitas kepada para kuli tinta untuk mengulas dan meliput Pulau Pasaran.

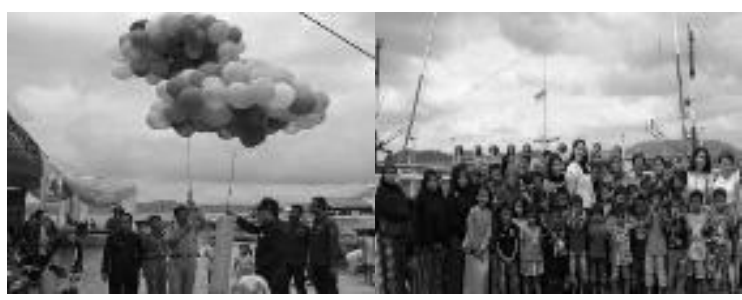

Gambar 4. Pencanangan Festival Pulau Pasaran dan kunjungan Puteri Indonesia

Bentuk pemberitaan meliputi program yang dijalankan atau memang secara khusus media membuat acara atau program tertentu, seperti: Indonesia Membangun (TVRI Lampung), Net TV (Net 12), RTV (Indonesia Banget), PKS TV, beberapa traveler di youtube dan instagram maupun media nasional seperti Antara, traveldetik.com, tempo.com, dan viva.co.id.

Penguatan image Pulau Pasaran sebagai destinasi minawisata dilakukan dengan menggerakkan ikon dan duta pariwisata (Muli-Mekhanai) Kota Bandar Lampung dan Putri Indonesia utusan Propinsi Lampung untuk berkunjung ke Pulau Pasaran (Gambar 4). Sehingga akan menarik minat jurnalis dalam pemberitaan dan peningkatan image wisata Pulau Pasaran.

Penyelenggaraan Festival Pulau Pasaran dilakukan dengan tujuan untuk meningkatkan icon pariwisata. Festivalisasi kegiatan di Pulau Pasaran dengan tema "Eksplore Pulau Pasaran" dimaksudkan untuk menarik minat wisatawan dan meningkatkan kesadaran masyarakat Pulau Pasaran mengenai pentingnya menjaga potensi alam dan lingkungan serta kesiapan masyarakat dalam menyambut wisatawan.

Kegiatan yang dilakukan berupa parade perahu hias, lomba masak serba ikan, lomba karya tulis, lomba fotografi, dan pengajian akbar. Selanjutnya adalah pencanangan minawisata oleh Walikota, Bapeda dan Rektor Universitas Lampung bersama dengan masyarakat Pulau Pasaran.

Pembangunan informasi secara daring dengan membuat website Pulau Pasaran, yaitu: www.pulaupasaran.com, dan instagram.explorepulaupasaran. Sehingga Pulau Pasaran sebagai virtual island yang mudah diakses (Ali et al., 2015).

Program ini dikembangkan oleh LPPM Universitas Lampung bekerjasama dengan Pemerintah Kota Bandar Lampung. Prinsip dari kegiatan ini menyangkut tiga hal: more digital more personal, more digital more professional, dan more global. Pemasaran secara digital lebih efektif seperti penghitungan feedback di media sosial.

Sedangkan program jejaring pariwisata dilakukan dengan menggandeng kelompok pecinta alam, backpacker, blogger, komunitas fotografi, agen perjalanan, dan hotel yang memungkinkan penyebaran informasi minawisata Pulau Pasaran semakin meluas.

\section{Membangun minawisata berbasis masyarakat}

Minawisata berbasis masyarakat menjadi strategi yang jitu karena di samping program pariwisata berjalan, 
daerah atau masyarakat akan mendapatkan keuntungan ekonomi dari adanya wisata yang dijalankan. Hanya saja ironisnya sebagian besar kawasan minawisata dikuasai pemodal asing baik areal ataupun manajemen wisatanya.

Sebagai contoh terdapat lebih dari 50 pulau di Indonesia yang wisata baharinya dikelola oleh investor asing baik dalam bentuk homestay, restoran hingga rental alat selam dan surfing, sementara pengusaha lokal dan warga pesisir hanya bekerja melayani investor asing, seperti pemandu turis, pekerja hotel, atau menjadi penjual sovenir asongan atau sekedar menjajakan makanan ringan.

Kondisi ini harus dibenahi agar masyarakat sekitar turut dapat merasakan keuntungan dari adanya minawisata di daerahnya. Pemerintah perlu menyiapkan masyarakat lokal agar memiliki peran yang lebih luas dalam pengelolaan minawisata menjadi berbasis masyarakat lokal.

Minawisata berbasis masyarakat menitikberatkan pada peran aktif komunitas. Hal tersebut didasarkan pada kenyataan bahwa masyarakat memiliki pengetahuan yang lebih tentang alam serta budaya yang menjadi potensi dan nilai jual sebagai daya tarik wisata di daerahnya.

Namun minawisata ini tidak lantas menjadikan masyarakat menjalankan usaha minawisata sendiri, melainkan tetap harus melibatkan pihak terkait baik pemerintah, dunia usaha dan LSM serta akademik menjadi suatu kemitraan sesuai peran dan keahlian masing-masing.

Dengan pengembangan minawisata berbasis masyarakat akan meningkatkan manfaat ekonomi dan kesejahteraan masyarakat seiring munculnya berbagai usaha dari pembentukan minawisata.

Program terkait yang telah dilakukan adalah dengan menginisiasi pembentukan Kelompok Sadar Wisata (POKDARWIS) Pulau Pasaran. Program ini baru tahap penjajakan. POKDARWIS bermaksud melalukan kegiatan melalui pendekatan kelembagaan (institutional approach) dengan cara melibatkan partisipasi aktif anggota kelompok sejak awal program. Oleh karena itu penguatan kelompok sadar wisata ini perlu dilakukan secara berkesinambungan.

Pada hakikatnya POKDARWIS dapat melaksanakan berbagai jenis kegiatan yang disesuaikan dengan keadaan dan kondisi kelompok. Namun semua jenis kegiatan tersebut diarahkan untuk:

a. Meningkatkan wawasan anggota Pokdarwis dalam bidang pariwisata.

b. Meningkatkan keterampilan anggota dalam mengelola usaha pariwisata

c. Mendorong masyarakat agar menjadi tuan rumah yang baik bagi wisatawan.

d. Mendorong masyarakat dalam meningkatkan daya tarik pariwisata

e. Mengumpulkan, mengolah, memberikan informasi kepariwisataan

Memberikan masukan kepada yang berwenang untuk meningkatkan pengembangan pariwisata.

\section{KESIMPULAN}

Potensi sumberdaya di Pulau Pasaran untuk dijadikan sebagai areal minawisata sangat beragam dan dapat meningkatkan kesejahteraan masyarakat. Penerapan minawisata berbasis masyarakat (community-based marine tourism) menjadi penting karena menitikberatkan peran aktif komunitas masyarakat lokal dalam pengelolaan wisata.

Program yang dilaksanakan berhasil menjadikan Pulau Pasaran semakin popular dikalangan masyarakat khususnya wisatawan ataupun beckpacker.

Pembangunan minawisata Pulau Pasaran sangat bergantung pada kesamaan presepsi dan kesatuan aksi antara masyarakat, pemerintah dan pihak swasta dalam mendukung terealisasinya wisata bahari, sehingga Pulau Pasaran menjadi icon baru dan komuditas yang menguntungkan bagi Kota Bandar Lampung (PAD) dan meningkatkan kesejahteraan masyarakat secara langsung. 


\section{UCAPAN TERIMA KASIH}

Kami menyampaikan terima kasih kepada LPPM Univeristas Lampung, UPPM Politeknik Negeri Lampung, Bappeda Kota Bandar Lampung dan Dinas Perikanan dan Kelautan Kota Bandar Lampung yang berpartisipasi dalam pembinaan dan pengembangan minawisata Pulau Pasaran.

\section{DAFTAR PUSTAKA}

Ali, M, E. Efendi, N.M. Noor. (2018). Proses pengolahan ikan teri (Stolephorus sp.) dan pemanfaatan limbahnya sebagai bahan baku pakan ikan dalam mendukung konsep zero waste. Jurnal Perikanan. 8(1): 47-54

Ali, M. (2015). Potensi pengembangan wisata bahari Pulau Pasaran, Bandar Lampung. Prosiding Seminar Nasional Swasembada Pangan, Politeknik Negeri Lampung, 29 April 2015: 568-575

Ali, M. H.W. Maharani, S. Hudaidah, H. Fornando. (2015b). Analisis kesesuaian lahan di perairan Pulau Pasaran provinsi Lampung untuk budidaya kerang hijau (Perna viridis). Maspari Journal: Marine Science Research, 7 (2): 57-64

Ali, M. L. Santoso, D. Fransiska. (2015a). Pengaruh substitusi tepung ikan dengan tepung kepala ikan teri terhadap pertumbuhan ikan nila (Oreochromis sp.), Jurnal Maspari Marine Sciences Researsch, 7(1): 63-70

Amanah, S. dan N. Utami. (2006). Perilaku nelayan dalam pengelolaan wisata bahari di kawasan Pantai Lovina, Bulelang, Bali. Jurnal Penyuluhan, 2(2): 83-90.

Arikunto, S. (2002). Prosedur penelitian: Suatu pendekatan praktek. Jakarta. Rineka Cipta.
Badan Perencanaan Daerah Kota Bandar Lampung. (2018). Monografi Pulau Pasaran, Bandar Lampung. Bappeda Kota Bandar Lampung.

Dinas Tata Kota Bandar Lampung. (2013). Gambar rencana DED Pulau Pasaran, Bandar Lampung. CV. Mega Cipta Perkasa. Lampung

Dinas Kelautan dan Perikanan Kota Bandar Lampung. (2014). Profil sentra pengolah hasil perikanan ikan Teri Siger Pulau Pasaran. DKP Kota Bandar Lampung. Lampung.

Hidayat, K, H. Yulianto, M. Ali, N.M. Noor, B. Putri. (2019). Performa pertumbuhan bawal bintang Trachinotus blochii yang dibudidaya dengan sistem monokultur dan polikultur bersama kerang hijau Perna viridis. Depik, Jurnal Ilmu-Ilmu Perairan, Pesisir dan Perikanan, 8(1): 1-8

Inskeep. (1991). Tourism planning: An integrated and sustainable development approach. New York. Van Nostrand Reinhoid.

Noor, N.M. (2015). Prospek pengembangan usaha budidaya kerang hijau (Perna viridis) di Pulau Pasaran, Bandar Lampung, Jurnal Aquasains, 3(2): 239-246

Noor, N.M., A.D. Astuti, E. Efendi. (2016). Performance of green mussel (Perna viridis) in monoculture and polyculture system within sea bass (Lates calcarifer). Jurnal Aquasains, 4(2): 389-400

Noor, N.M., H. Nursyam, M.S. Widodo, Y. Risjani. (2019a). Biological aspects of green mussels Perna viridis cultivated on raft culture in Pasaran coastal waters, Indonesia. AACL Bioflux, 12(2): 448-456

Noor, N.M., H. Nursyam, M.S. Widodo, Y. Risjani. (2019b). Identification of green mussel from Lampung Bay, Indonesia by using a 
morphological and molecular approach. Bioscience Research, 16(2): 1395-1404

Pulau Pasaran. (2014). Data kependudukan Pulau Pasaran. Bandar Lampung. Sensus Penduduk Pulau Pasaran. Kota Bandar Lampung.

Putri, B. N.M. Noor, M. Ali. (2018). Pembinaan usaha budidaya kerang hijau dan ikan di Pulau Pasaran, Lampung. Jurnal Sakai Sembayan, 2(1): 30-35

Rosalina, Y., Alnopri dan Prasetyo. (2010). Desain kemasan untuk meningkatkan nilai tambah madu bunga kopi sebagai produk unggulan daerah. Jurnal Agroindustri, 2(1): 2088-5369.

Sulistiyanti, S.R. M. Ali, E. Efendi, W. Winarto. (2016). Pengering lapis tipis (thin layer drying /TLD) ikan teri berbasis tenaga surya. JPKM (Jurnal Pengabdian Masyarakat) Universitas Negeri Medan, 22(3): 110-113

Sulvina, N.M. Noor, H.W. Maharani, S. Hudaidah. (2015). Pengaruh perbedaan jenis tali terhadap tingkat penempelan benih kerang hijau (Perna viridis). e-Jurnal Rekayasa dan Teknologi Budidaya Perairan, 4(1): 4(1): 471-478

Waryono, T. 2000. Aspek pengembangan Desa Wisata Nelayan Kampung Laut Segara Anakan, Cilacap. Semiloka Kelautan Menjelang Otonomi Daerah, Kerjasama Pemda Cilacap dengan Departemen Perikanan dan Kelautan; 25 Nopember 2000 di LP. Nusakambangan, Cilacap. 
